\title{
Entamoeba histolytica and Entamoeba disparinfections as detected by monoclonal antibody in an urban slum in Fortaleza, Northeastern Brazil
}

\author{
Infecção pela Entamoeba histolytica and Entamoeba dispar detectada através de anticorpos \\ monoclonais nas fezes em uma Comunidade Urbana em Fortaleza, Nordeste do Brazil
}

\author{
Lúcia Libanez Bessa C. Braga', Manuela L. Gomes', Melissa W. da Silva1, \\ Clece Paiva ${ }^{1}$, Andréa Sales $^{1}$ and Barbara J. Mann ${ }^{2}$
}

\begin{abstract}
In this study the authors used the ELISA-based antigen detection tests that distinguish $\mathrm{E}$. histolytica from $\mathrm{E}$. dispar to examine the prevalence of $\mathrm{E}$. histolytica infection in individuals from an urban slum in Fortaleza, Northeastern, Brazil. This test has a sensitivity and specificity that is comparable to PCR and isoenzyme analysis, which is the gold standard. Single stools samples were obtained from 735 individuals. The prevalence of E. histolytica infection was $14.9 \%(110 / 735)$ and $25.4 \%(187 / 735)$ for $\mathrm{E}$. dispar-E. histolytica complex. The most affected age group for $\mathrm{E}$. histolytica /E. histolytica-E. dispar infection was the 1-5 year olds but there was no remarkable decrease with age. There was no significant difference in colonization rates between males and females. The results from this survey demonstrate that $\mathrm{E}$. histolytica is highly prevalent in the Community studied. Furthermore, it offers promise for the antigen detection test as a sensitive and technically simple tool for detecting $\mathrm{E}$. histolytica infection in the field.
\end{abstract}

Key-words: E. histolytica E. histolytica-E. dispar complex. Epidemiology. Brazil.

Resumo Neste estudo, utilizamos testes de detecção antigênica baseada em ELISA que distinguem entre E. histolytica e E. dispar, para examinar a prevalência das infecções por $\mathrm{E}$. histolytica em indivíduos de uma favela urbana em Fortaleza, no nordeste do Brasil. Esse teste possui sensibilidade e especificidade comparáveis às da PCR e da análise isoenzimática, que é o padrão ouro. Amostras simples de fezes foram obtidas de 735 indivíduos. A prevalência da infecção por E. histolytica foi de 14,9\% (110/735) e de 25,4\% (187/735) para 0 complexo E. dispar-E. histolytica. A faixa etária mais acometida por infecções com $\mathrm{E}$. histolytica/E. histolyticaE. dispar foi a de 1-5 anos, mas não houve redução significativa com a idade. Não houve diferença significativa nas taxas de colonização entre homens e mulheres. Os resultados desta pesquisa mostram que E. histolytica é altamente prevalente na comunidade estudada. Alem disso, oferecem esperança para o uso do teste de detecção antigênica como um recurso sensível e tecnicamente simples para a detecção de infecção com E. histolytica no campo.

Palavras-chaves: E. histolytica. Complexo E. histolytica-E. dispar. Epidemiologia. Brasil.

Amebiasis is a significant health problem in developing countries. Entamoeba histolytica infection is responsible for up to 100,000 deaths per year ${ }^{19}$. Previously E. histolytica had been classified as consisting of pathogenic and nonpathogenic zymodemes. However this parasite is now recognized as two genetically distinct species, the invasive parasite E. histolytica, which is the etiologic agent of amebic colitis and liver abscess, and the noninvasive parasite Entamoeba dispar which has never been associated with disease ${ }^{716} 18$.
The diagnosis of amebiasis by microscopic identification of cysts or trophozoites in the stool is time consuming, requires expertise and does not distinguish pathogenic E. histolytica from nonpathogenic E. dispar. It is at best only $60 \%$ sensitive 8913 . Culture is more sensitive than microscopy, and isoenzyme analysis of cultured amebae enables the differentiation of $E$. histolytica from E. dispar. However, amebic cultures and isoenzyme analysis require a week to complete and are negative in many microscopy-positive stools ${ }^{13}$.

\footnotetext{
1. Clinical Research Unit-University Hospital Walter Cantídio/Department of Physiology and Pharmacology and Department of Medicine, Federal University of Ceará, Fortaleza, Brazil; 2.Divisions of Infectious Diseases and Geographic Medicine, University of Virginia, Charlottesville, Virginia.

Financial support: This work was supported by an NIH Fogarty Research Collaboration Award TW00509 to B.J.M and a grant from CNPq to L.L.B.C.B.

Address to: Dra Lucia Libanez Bessa C. Braga. Clinical Research Unit-University Hospital Walter Cantidio. Av. Jose Bastos 3390, sala 90, 60436-170 Porangabussu, Fortaleza CE, Brazil

Tel: 5585 223-6982

E-mail libanes@brhs.com.br

Recebido para publicação em 10/10/2000
} 
New approaches to the detection of E. histolytica and E. dispar are based on E. histolytica antigen detection in stool ${ }^{191011}$ and detection of E. histolytica-specific DNA by PCR amplification ${ }^{3} 52015$. Haque and col. compared PCR, antigen detection and isoenzyme analysis for specific detection of $E$. histolytica in fresh stool samples. All three techniques showed excellent correlation. Only the enzyme linked immunosorbent assay, that distinguishes between E. histolytica and $E$. dispar antigens, was both rapid and technically simple. These ELISA kits use monoclonal antibodies (Mab) directed against cross-reactive and species- specific epitopes of the Gal/GalNAc lectins from $E$. histolytica and E. dispar. The E. histolytica Test specifically detects $E$. histolytica while the Entamoeba Test detects the $E$. histolytica-E. dispar complex.

The authors have previously shown that amebiasis in Gonçalves Dias and nearby communities is frequent, however the prevalence of $E$. histolytica and $E$. dispar were not well characterized ${ }^{4}$. Therefore an E. histolytica antigen detection test was used to examine the prevalence of $E$. histolytica and $E$. dispar within an urban slum in Northeastern Brazil.

\section{MATERIAL AND METHODS}

Subjects enrolled in this study were from Gonçalves Dias, a community of 1900 inhabitants, located in an urban slum (favela) in Fortaleza, Brazil and nearby slum communities. After a detailed explanation of the study, informed consent was obtained in Portuguese for all subjects that participated in the study. The use of human subjects was approved by Committee for Clinical Investigation at the Federal University of Ceará, and at the University of Virginia. Each subject was questioned for symptoms of intestinal/extraintestinal amebiasis, dysentery, fever and history of drug ingestion.

Collection of samples. A single fresh stool specimen was collected from each person without fixative, stored at $2-8^{\circ} \mathrm{C}$ and tested with the Entamoeba Test and E. histolytica Test kits within $24 \mathrm{~h}$. The specimens were stored at $-20^{\circ} \mathrm{C}$ if the tests could not be performed within $24 \mathrm{~h}$. Microscopic stool examination was realized by direct wet mount of merthiolate-iodineformaldehyde preserved stools by sedimentation method as described by Hoffman ${ }^{12}$.
Enzyme-linked immunosorbent assay for detection of Gal/GalNAc lectin in stools. The Entamoeba Test (designed to detect but not differentiate $E$. histolytica and $E$. dispar in stool specimens) and Entamoeba histolytica Test (designed to specifically detect $E$. histolytica in stool) were performed according to the manufacturer's instructions (Tech Lab, Inc., Blacksburg, VA). Briefly, coated microtiter wells (provided with the kit) were incubated with $0.1 \mathrm{ml}$ of diluted specimen (stool specimen diluted $1: 1$ in diluent provided with the kit) and 1 drop of Mabenzyme conjugate for $2 \mathrm{~h}$ at room temperature. The contents of the well strips were then shaken out and washed four times in the wash solution. After washing, residual liquid was removed by striking the strip once against a paper towel, substrate solutions were added, and incubated for $10 \mathrm{~min}$ at room temperature. Intensifier was then added, and after an additional 10 minutes of incubation the well strips were read in a microtiter plate reader (Titertek Multiskan; Flow Laboratories, McLean, VA) at 450nm. Positive results were defined as an optical density reading of $>0.05$ after subtraction of the negative control optic density.

Statistical difference was analyzed using the $\mathrm{X}^{2}$ (chi-square) test.

\section{RESULTS}

During the study period from 1996 to 1998 , stool samples from 599 individuals were collected, and examined for parasites by microscopy and for $E$. histolytica-E. dispar complex and E. histolytica by ELISA. An additional 136 stools were examined for $E$. histolytica-E. dispar complex and E. histolytica by antigen detection kit only. The mean age of the subjects was 17 years (1 year to 80 years); $43.5 \%$ (320/735) were males and $56.5 \%$ (416/735) females. According to the questionnaires all individuals were asymptomatic.

The overall colonization rate with various parasites by microscopy was 52\% (312/599) with
$50.6 \%$ (158/312) males and 49.3\% (154/312) females. Table 1 displays the prevalence rates of infection by individual parasites species in the population sample. Among parasitized individuals 43.9\% (137/312) had mixed infections with more than one parasite species. Ascaris lumbricoides was the most prevalent parasite at $32.4 \%(194 / 599)$. Very few cases of Giardia lamblia infection were found $(2.8 \% ; 17 / 599)$. E. disparE. histolytica complex was detected by microscopy in $7.5 \%(45 / 599)$ of the stools, with a mean of 9.5 years of age (range 6-67 years) with $37.8 \%(17 / 45)$ males, and $62.2 \%(28 / 45)$ females. Entamoeba coli infection was found in $15.8 \%(95 / 599)$. 
The prevalence of E. dispar-E. histolytica complex detected by antigen detection kit was $25.4 \%(187 / 735)$, mean age 27 years (range $1-72)$, with $48.1 \%(90 / 187)$ males and $51.9 \%(97 / 187)$ females. The prevalence of $E$. histolytica infection was $14.9 \%(110 / 735)$ with a mean age of 9 years (range 3-64), 51\% (57/110) males and 48.2\% (53/ 110) females. Figure 1 shows age-related rates of colonization with E. histolytica and E. disparE. histolytica complex.

Table 1 - Prevalence of protozoan parasites in stool.

\begin{tabular}{|c|c|c|}
\hline Parasite & Prevalence( $\%)$ & Positive $(\mathrm{rr})^{\mathrm{a}}$ \\
\hline Ascaris lumbricoides & 32.7 & 196 \\
\hline Entamoeba colib & 15.8 & 95 \\
\hline Tricuris trichiura & 12.3 & 74 \\
\hline E. histolytica-E. dispar complex & 7.7 & 46 \\
\hline Enterobius vermiculares & 2.8 & 17 \\
\hline Endolimax nana ${ }^{b}$ & 2.3 & 14 \\
\hline Giardia lamblia & 2.8 & 17 \\
\hline Hymenolepis nana & 2.5 & 15 \\
\hline Strongyloides stercoralis & 2.3 & 14 \\
\hline lodoamoeba buetschlii & 2.0 & 12 \\
\hline Ancylostoma & 2.0 & 12 \\
\hline Chilomastix mesnilib & 0.3 & 2 \\
\hline
\end{tabular}

a Total of 599 samples were tested

${ }^{\mathrm{b}}$ Commensal organism

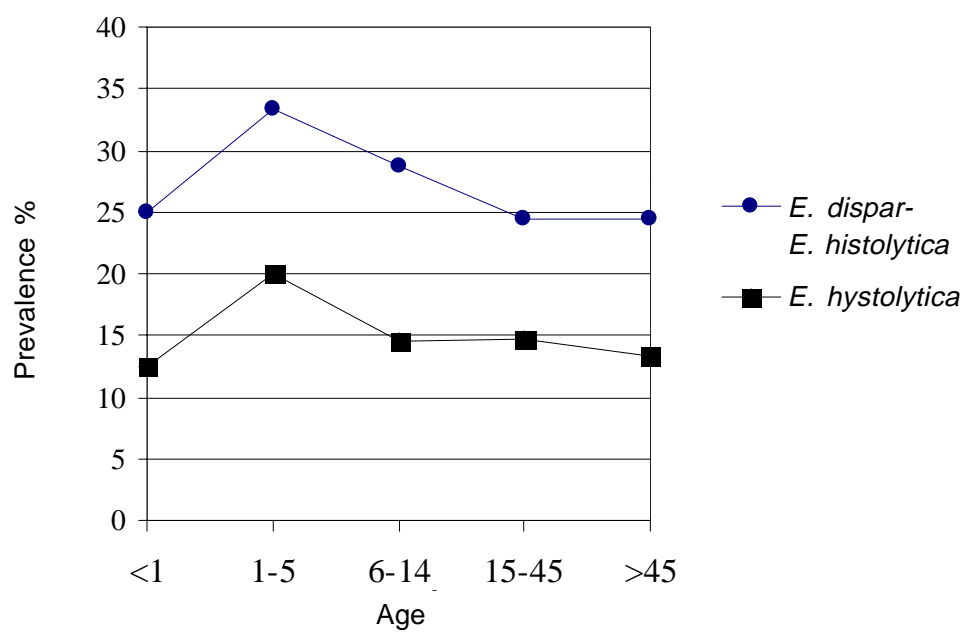

Figura1. Age-related rates and stool colonization with E. histolytica and E. histolytica-E. dispar solid squares indicated individuals colonized with $\mathrm{E}$. histolytica and with solid circles individuals colonized with E. disparE. histolytica complex.

\section{DISCUSSION}

Infection with E. histolytica is a severe health problem in many tropical and subtropical areas of the world, especially in developing countries. Most epidemiological studies of $E$. histolytica infection were performed before the distinction of two separate species, E. dispar and E. histolytica, was estabilished ${ }^{7}$.
This has raised the question of the validity of these studies. There is a clear need to perform epidemiological studies in amebiasis which distinguish the two species of Entamoeba before one can state the true prevalence and impact of $E$. histolytica. 
In this study, antigen detection was used to distinguish $E$. histolytica from $E$. dispar. This test fulfills the requirements for use in epidemiologic investigations with large samples, as it is easy to use, rapid, and has high sensitivity and specificity ${ }^{9}$. In the present survey of 735 individuals, using an ELISAbased antigen detection kit on stools, approximately $25 \%$ were E. histolytica-E. dispar complex positive, and $15 \%$ E. histolytica positive. These results show that infection by $E$. dispar-E. histolytica complex and $E$ histolytica is endemic in this region of Northeastern Brazil. This is consistent with the authors' previous observation that the overall seropositivity for anti- $E$. histolytica Gal/GalNAc lectin antibodies was $24.7 \%{ }^{4}$.

Studies of $E$. histolytica infection in Brazil among low-income populations have shown a difference between the North, Northeast and South regions. Zymodeme analyses indicated that in the Amazon region (North) both $E$. histo1ytica and E. dispar were found with higher prevalence for E. histolytica while in Pernambuco in Northeastern Brazil E. dispar predominated. The methodologies that were used to detect Entamoeba species varied including serologic tests, zymodeme analysis, and $\mathrm{PCR}^{2} 1417$.

Microscopic examinations were performed in 599 stools and revealed the presence of other intestinal protozoans as well as helmintic parasites in approximately $52 \%$ of the individuals. E. histolytica$E$. dispar complex were detected in $8 \%$ of the stools by microscopy. It was not an objective of this study to compare the detection of E. histolytica-E. dispar complex by antigen detection test with microscopy, however Haque and col. have shown that microscopy is $37 \%$ sensitive and antigen detection test is $94 \%$ sensitive when compared with culture ${ }^{9}$.

As shown in Figure 1, the prevalence of E. histolytical $E$. dispar and $E$. histolytica was particularly high in the 1-5 year-old age group, but with no remarkable decrease with age. These results suggest a continuous exposure to the parasite throughout life and if immunity exists it does not protect well against colonization. There was no difference in colonization rates between males and females.

In this study we did not identify any significant association of infection by $E$. dispar- $E$. histolytica or $E$. histolytica with diarrhea or other intestinal disorders. This observation is consistent with longitudinal studies of individuals carrying E. histolytica, where little or no risk of intestinal disease was found and most individuals cleared their infections within six months ${ }^{12}$. All individuals with $E$. histolytica positive stools were asymptomatic. Repeated exposure to E. histolytica with the development of partial immunity to this parasite could explain the low rate of symptoms despite a high rate of infection by $E$. histolytica. Other possibility is that there may be restricted invasiveness of some strains of $E$. histolytica. Also, since this study was a one-time sampling it was not possible to ascertain for how long the colonized subjects remained asymptomatic.

In conclusion, the present study has demonstrated that $E$. histolytica and E. dispar infections are very frequent in this slum-dwelling population sample from Fortaleza Northeastern Brazil. Prospective cohort studies are needed to clearly define the epidemiology of $E$. histolytica infection.

\section{REFERENCES}

1. Abd-alla MD, Jackson TFHG, Gathiram V, Hawey AME, Ravdin JI. Differentiation of pathogenic Entamoeba histolytica infections from nonpathogenic infections by detection of galactose-inhibitable adherence protein antigen in sera and feces. Journal of Clinical Microbiology 31: 2845-2850, 1993.

2. Aca IS, França JRE, Nozaki T. Entamoeba histolytica zymodemes in children of Osasco, São Paulo. Revista do Instituto de Medicina Tropical de São Paulo 35: 581-582, 1993.

3. Acuna-Soto R, Samuelson J, Girolami PDE. Application of the polymerase chain reaction to the epidemiology of pathogenic and nonpathogenic Entamoeba histolytica. American Journal Tropical Medicine and Hygiene 48: 58-70, 1994.

4. Braga LL, Lima AAM, Sears CL, Newman RD, Wuhib T, Paiva CA, Guerrant RL, Mann BJ. Seroepidemiology of Entamoeba histolytica in a slum in northeastern of Brazil. American Journal Tropical Medicine Hygiene 55: 693-697, 1996.

5. Britten D, Wilson SM, McNerney R, Moody AH, Chiodini PL, Ackers JP. An improved colorimetric PCR-based method for detection and differentiation of, Entamoeba histolytica and Entamoeba dispar in feces. Journal of Clinical Microbiology 35: 1108-1111, 1997.
6. Clark CG, Diamond LS. Entamoeba histolytica: an explanation for the reported conversion of "nonpathogenic" amebae to the "pathogenic" form. Experimental Parasitology 77: 456-460, 1993.

7. Diamond LS, Clark CG. A redescription of Entamoeba histolytica Shaudin 1903 (amended Walker 1911) separating it from Entamoeba histolytica dispar (Brumpt 1925). Journal Eukaryotic Microbiology 40:340-344, 1993.

8. Gonzalez-Ruiz A, Haque R, Rehman T, Aquire A, Hall A, Giuhl F, Warhurst DC Miles MA Diagnosis of amebic dysentery by detection of Entamoeba histolytica fecal antigen by an invasive strain-specific, monoclonal antibody-based enzyme-linked immunosorbent assay. Journal of Clinical Microbiology 32: 964970, 1994.

9. Haque R, Faruque ASG, Hahn P, Lyerly DM, Petri Jr WA. Entamoeba histolytica and, Entamoeba dispar infection in children Bangladesh. Journal of Infectious Diseases 175: 7347361997.

10. Haque R, Kress K, Wood S, Jackson TFHG, Byerly DM, Wilkeins T, Petri Jr WA. Diagnosis of pathogenic Entamoeba histolytica 
infection using a stool ELISA based on monoclonal antibodies to the galactose-specific adhesins. Journal of Infectious Diseases 167: 247-249, 1993.

11. Haque R, Neville LM, Hahn P, Petri Jr WA Rapid diagnosis of Entamoeba infection by using the Entamoeba and Entamoeba histolytica stool antigen detection kits. Journal of Clinical Microbiology 33: 2558-2561, 1995.

12. Hoffman WA, Pons JA, Janner JL. The sedimentation concentration method in Schistosomiasis mansoni. Public Health Tropical Medicine 9: 283-98, 1934.

13. Jackson TFHG, Gathiran V, Simjee AE. Seroepidemiologic study of antibody responses to, the zymodemes of Entamoeba histolytica. Lancet 1: 716-721, 1985.

14. Krogstad DJ, Spencer HC, Healy GR, Gleason NN, Sexton DJ, Herror CA. Amebiasis: epidemiologic studies in the United States. 1971-1974 Annals of Internal Medicine 88: 89-97,19711974, 1978.

15. Nozaki T, Okuzawa E. Zymodemes of Entamoeba histolytica isolated in the Amazon and the north-east of Brazil. Transactions Royal Society of Tropical Medicine and Hygiene 84: 387-388, 1990.
16. Romero JL, Descoteaux S, Reed S, Orozco E, Santos J, Samuelson $J$. Use of polymerase chain reaction and non radioactive DNA probes to diagnose Entamoeba histolytica in clinical samples. Archives of Medical Research 23: 277-279, 1992.

17. Sargeaunt PG, Williams JE, Grene JD. The differentiation of invasive and non-invasive Entamoeba histolytica by isoenzyme electrophoresis. Transactions Royal Society of Tropical Medicine and Hygiene 72:519-521, 1978.

18. Tachibana H, Kobayashi S, Paz KC Analysis of pathogenicity by restriction-endonuclease digestion of amplified genomic DNA of Entamoeba histolytica isolated in Pernambuco, Brazil. Parasitology Research 78: 433-436, 1992.

19. Tannich E, Burchard GD. Differentiation of a pathogenic from nonpathogenic Entamoeba histolytica by restriction fragment analysis of a single gene amplified in vitro. Journal of Clinical Microbiology 29: 250-255, 1991.

20. Tannich E, Horstmann RD, Knobloch J, Arnold HH. Genomic differences between pathogenic and nonpathogenic Entamoeba histolytica. Proceeding of National Academy of Science USA 86:5118-5122, 1989.

21. World Health Organization. Amebiasis. WHO Weekly Epidemiology Records 72: 97-100, 1997. 